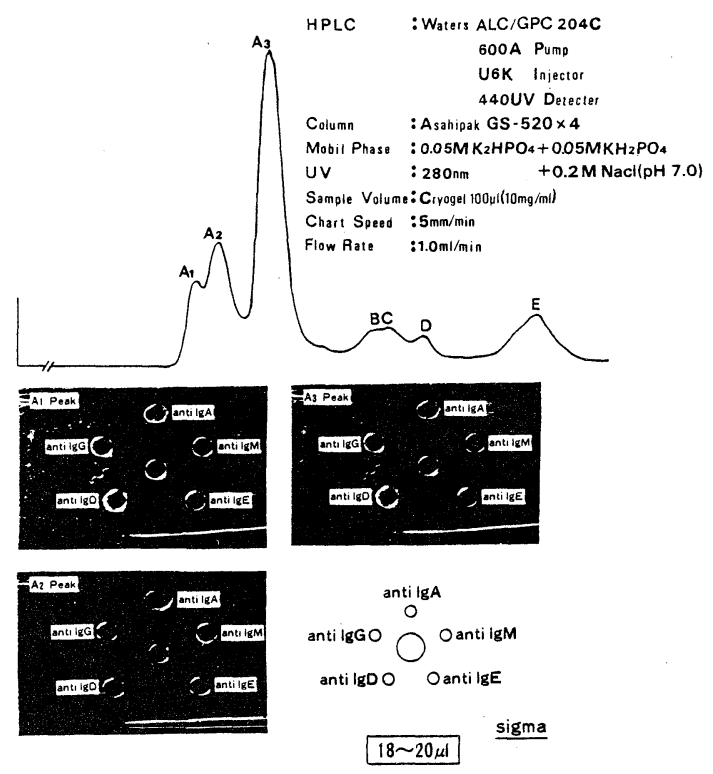

Fig. 3. Ouchterlony test of $A_{1}, A_{2}$ and $A_{3}$ peaks analyzed by HPLC.

for RA therapy.

We measured IgG, IgA, IgM, C3, C4 and im- mune complex in $10 \mathrm{mg}$ cryogel dissolved by isotonic saline. Concentration of immune complex was not high. From this result, we concluded that immune complex is not chief component of cryogel.

To examine the relation between A1, A2 and A3 of cryogel and immunoglobulins, ouchterlony test was performed. Fig. 3 shows that immunoglobulins, especially native IgM, were not component of cryogel.

\section{REFERENCES}

1) Yamagata J, et al: Therapeutic plasma exchange for rheumatoid disease, In Plasma Exchange, ed. HG Sieberth, Schattauer Verlag Stuttgart, New York, $1980, \mathrm{p} 267$.

2) Agishi $\mathrm{T}$, et al: Double-filtration plasmapheresis. Trans Amer Soc Artif Intern Org 26: 406, 1980.

3) Nose $Y$, et al: Therapeutic membrane plasmaphesis, In Therapeutic Plasmapheresis (I), ed. T Oda, Schattauer Verlag Stuttgart, New York, 1981, p 3.

4) Kuroda S, et al: Effects of cryofiltration on patients with rheumatoid arthritis and the analysis of cryoprecipitates, In Therapeutic Plasmapheresis (III), ed. T Oda, SChattauer Verlag Stuttgart, New York, $1983, \mathrm{p} 265$.

\title{
5. Plasma Exchange Therapy in Systemic Lupus Erythematosus: Its Indication and Evaluation
}

\author{
Hidehiro Amemiya and Hiroshi Sato
}

\author{
Department of Medicine, IV, Tokyo Women's Medical College, Tokyo
}

The purpose of this study is to clarify whether the measurement of $\mathrm{T}$ cell subsets, the splenic function, determined by the radiolabelled heatdamaged red blood cells and the chronicity index of the renal biopsy specimen are useful or not to determine the indication of plasma exchange therapy for patients with SLE.

Plasma exchange (PEx) was performed by the centrifugation method or double filtration plasmapheresis. Series of PEx consisted of 3 to 6 procedures and $5 \%$ albumin solution was used for the substitution fluid.

In 16 patients with SLE, the measurement of $\mathrm{T}$ cell subsets was carried out before and after series of PEx by the flow cytometry using OKT monoclonal antibody (Ortho Pharmaceutical Corp.).

The splenic function was studied in 7 patients by the radiolabelled heat-damaged red cells before PEx and repeated within 1 to 5 weeks after series of PEx in 4 of 7 patients.

In 8 patients, renal biopsy was performed. The specimen was examined under the light microscopy and the lesions were scored as the chronicity index which is modified by Morel-Maroger's sclerosing index.

There were no significant changes in OKT3, 4 and 8 positive cells before and after PEx and also 

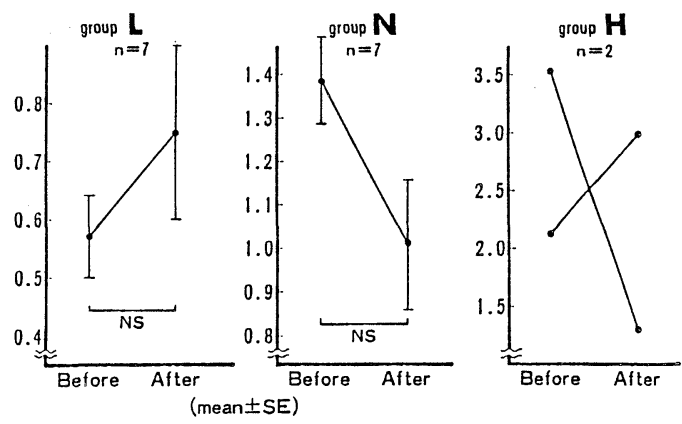

Fig. 1. Changes in OKT4/8 ratio by series of PEx.

in OKT4/8 ratio. Moreover, when the patients with SLE were divided into three group by OKT4/ 8 ratio $($ low $=\mathrm{L}$, normal $=\mathrm{N}$ and high $=\mathrm{H}$ ), PEx produced no significant effect on the ratio in each group (Fig 1). Therefore, the measurement of $\mathrm{T}$ cell subsets seemed to be inappropriate to determine the indication of PEx.

The splenic function is usually expressed as $\mathrm{T} 1 / 2$. The mean $\mathrm{T} 1 / 2$ in controls is 13 , patients with and without active symptoms is 31 and 13 minutes respectively. However, there was no correlation between $\mathrm{T} 1 / 2$ and circulating immune complexs, titer of anti-DNA antibody, ESR or CRP. In 4 patients with repeated studies before and after PEx, T1/2 reduced rapidly in association with the improvement of symptoms (Fig 2). In only one of these 4 patients, circulating immune complexes were detected. From these results, the splenic function was thought to be valuable to determine the indication of PEx and to evaluate the effect of PEx.

In 8 patients received renal biopsy, the mean of the chronicity index (CI) was $6.6 \pm 1.8$. Among these patients, 6 were the high, 1 was the intermediate and 1 was the low score group. In 7 patients with high or intermediate score, Ccreat. were below $45 \mathrm{ml} / \mathrm{min}$. before PEx. However, within one year after PEx, 25\% or more improvement of the renal function was observed in 5 of these 7 patients (Fig 3). Further, in these 7 patients with nephrotic syndrome, 6 showed the reduction in urinary protein excretion within one year. Although the poor prognosis was sus-

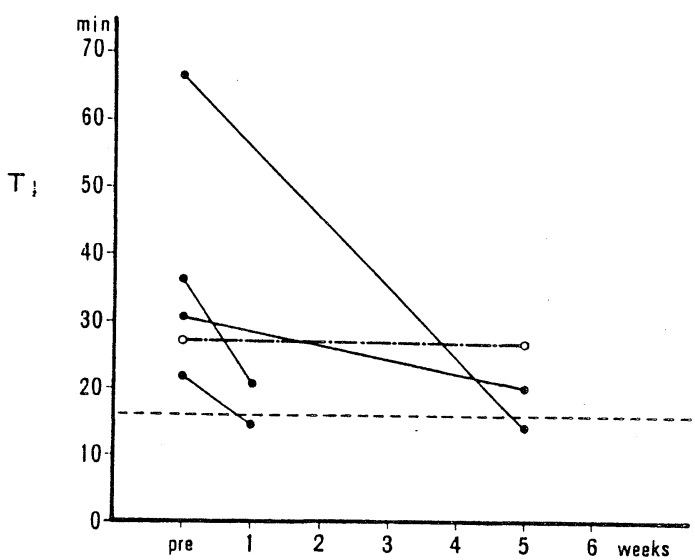

Fig. 2. Changes in $\mathrm{T} 1 / 2$ before and after treatment. $\mathrm{PEx}+$ steroid steroid alone $0-\ldots$

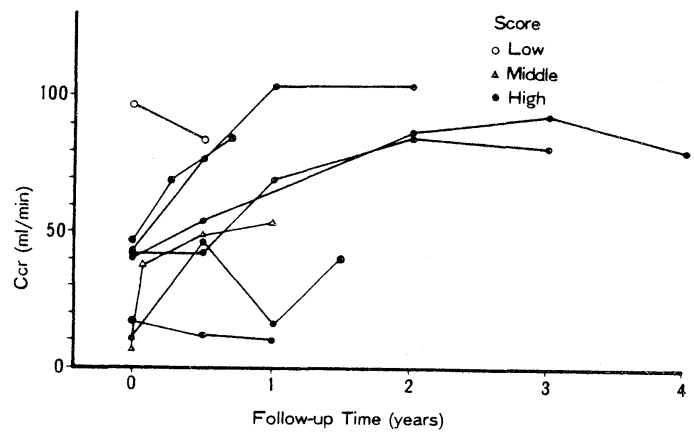

Fig. 3. Changes in Ccreat. after PEx.

pected in patients with high score of CI, PEx appears to be worthwhile to try for the patients of this high score group.

Therefore, at present time, the following conclusion is obtained.

(1) The results of $\mathrm{T}$ cell subsets is not adequate to determine the indication of PEx.

(2) The results of the splenic function coincided with the disease activity. Effectiveness of PEx is not infrequent in the patients with the splenic dysfunction.

(3) The improvement of the renal function is possible in the patients with high score of $\mathrm{CI}$ and appears to be useful to determine the indication of PEx. 